\title{
Intracellular Motility of Intermediate Filaments
}

\author{
Rudolf E. Leube, Marcin Moch, and Reinhard Windoffer
}

Institute of Molecular and Cellular Anatomy, RWTH Aachen University, 52074 Aachen, Germany

Correspondence: rleube@ukaachen.de

\section{SUMMARY}

The establishment and continuous cell type-specific adaptation of cytoplasmic intermediate filament (IF) networks are linked to various types of IF motility. Motor protein-driven active transport, linkage to other cellular structures, diffusion of small soluble subunits, and intrinsic network elasticity all contribute to the motile behavior of IFs. These processes are subject to regulation by multiple signaling pathways. IF motility is thereby connected to and involved in many basic cellular processes guarding the maintenance of cell and tissue integrity. Disturbances of IF motility are linked to diseases that are characterized by cytoplasmic aggregates containing IF proteins together with other cellular components.

\section{Outline}

1 Introduction

2 IF motility is needed for cell type- and function-dependent formation, maintenance, and reorganization of cytoplasmic IF networks

3 IF motility is multimodal

4 IF motility is determined by actin filaments and microtubules

5 IFs are cargoes of motor proteins

6 The dynamics of IFs are subject to regulation
7 Intracellular IF motility is an essential feature of the keratin turnover cycle in epithelial cells

8 Neuronal IF motility determines axonal diameter and slow axonal transport

9 IF motility is linked to cell migration

10 Stress induces alterations in IF motility

11 Disturbances of intracellular IF motility are linked to disease

12 Conclusion

References 
R.E. Leube et al.

\section{INTRODUCTION}

The view of intermediate filaments (IFs) as rather static cellular elements was fundamentally changed by monitoring fluorescently tagged IFs in living cells, which revealed their highly dynamic nature (Ho et al. 1998; Yoon et al. 1998; Windoffer and Leube 1999; Prahlad et al. 2000; Roy et al. 2000; Shah et al. 2000; Wang et al. 2000). Since then, our knowledge of the complex context-dependently regulated types of IF motility has been growing steadily. But we are only now starting to understand the molecular details governing these complex processes. The current challenge is not only to dissect the underlying pathways and their cell type- and function-dependent interactions but to relate these findings to relevant in vivo situations. Yet, it is obvious that IF motility is crucial for overall organismal homeostasis, as depicted in the scheme of Figure 1. At steady state, IF motility is required to continuously replenish used-up, dysfunctional, and degraded network components to ensure functional IF network maintenance. Altered IF motility is coupled to network reorganization during differentiation and dedifferentiation, it is linked to network disassembly and reassembly during cell division, and it is associated with localized changes in network turnover in migrating cells. In addition, IF network motility is involved in network responses to various stresses, including physical stimuli, chemical challenges, and microbial infections, that affect network stability. Disturbances of IF network motility and its regulation are implicated in diseases, which are characterized by prominent cytoplasmic IF aggregates.

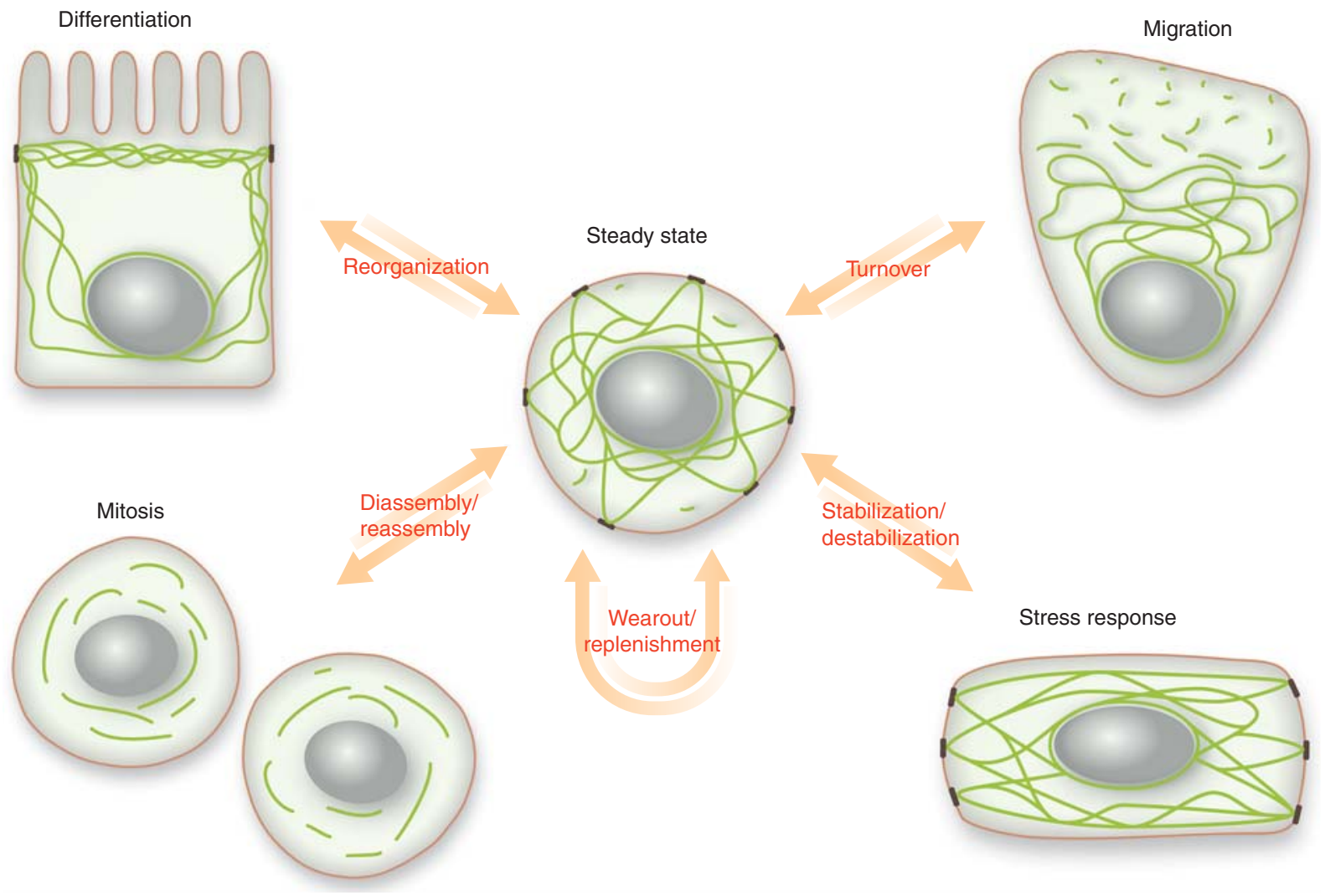

Figure 1. Situations requiring motility of the intermediate filament (IF) network. Differentiation, migration, mitosis, and stress responses are all associated with a dynamic restructuring of the IF cytoskeleton that requires a high degree of IF motility. Differentiation is coupled to changes in IF composition, resulting in unique subunit combinations with distinct dynamic and biomechanical properties adapting to cell type-specific requirements through cytoskeletal reorganization into spatially defined networks. In migrating polarized cells, net assembly occurs at the leading edge in contrast to net disassembly at the rear end of the cell. At the cell front, network plasticity is enhanced by increased subunit turnover. Network turnover is additionally fueled by continuous biosynthetic replenishment, which is also needed to compensate for physiological wear out through subunit degradation. Biosynthesis and degradation in combination with cyclic subunit turnover are the basis of the equilibrium at steady state. During cell division, the IF network is disassembled and reorganized to various degrees depending on the cell type. At the end of mitosis, a functional interphase network is reestablished from the different disassembly intermediates. A major function of the IF network is to respond to stress, which increases or decreases network stability. 
Here, we will review current knowledge on the different dynamic processes regulating IF architecture and motility in a context-dependent fashion, focusing, in particular, on mesenchymal, epithelial, and neuronal cells. For a general introduction to the structure and functions of IFs, see Herrmann and Aebi (2016).

\section{IF MOTILITY IS NEEDED FOR CELL TYPE- AND FUNCTION-DEPENDENT FORMATION, MAINTENANCE, AND REORGANIZATION OF CYTOPLASMIC IF NETWORKS}

The IF cytoskeleton fulfills major functions in cell and tissue architecture. These functions are coupled to a high degree of stability and mechanical resilience of the IF network. Network stability, however, is continuously challenged by dynamic cellular processes, such as movement of intracellular organelles and overall changes in cell shape. Furthermore, IFs perform a universal function as "dashpots" to protect cells against physical, chemical, and microbial insults. In all these situations, cytoplasmic IFs have to be moved and are rearranged to maintain the structural and functional integrity of cells and tissues.

In addition, intracellular IF motility is needed to set up cell type-specific networks in defined cytoplasmic subdomains. Parallel bundles of tightly packed neurofilaments are localized along axonal processes of neurons, membraneanchored meshworks connect components of the Z-disks to the plasma membrane in striated muscle, paracrystalline fibers of vimentin, phakinin, and filensin are encountered in lens cells, subapically enriched networks are established in enterocytes, cortical meshworks are usually found in hepatocytes, and pancytoplasmic, desmosome-anchored three-dimensional networks of thick-filament bundles are characteristic for epidermal keratinocytes. Specific topological cues and/or transport machineries are obviously necessary to support the establishment of these different types of IF network arrangements. Furthermore, mechanisms must be in place to maintain these specialized distribution patterns (e.g., see Iwatsuki and Suda 2010 and Carberry et al. 2012 for polarized epithelial cells).

The necessity for IF motility becomes even more obvious in situations requiring overall cytoskeletal restructuring. Migrating cells, for example, are characterized by a highly polarized organization, which is coupled to IF network extension at the leading edge and compensatory network reduction in the trailing part of the cell. The associated differential local network dynamics affect biomechanical properties supporting defined cell-shape changes and altered organelle trafficking in specific subcellular domains. In mitotic cells, the IF networks must be distributed to both daughter cells; this distribution, depending on the cell type, is accompanied by localized or even generalized network disassembly and subsequent reassembly.

\section{IF MOTILITY IS MULTIMODAL}

Different types of IF motility can be distinguished: motor protein-driven active transport, passive translocation by attachment to dynamic structures, and diffusion and intrinsic viscoelastic recoil. In contrast to attachment of IFs to specialized membrane sites such as desmosomes and hemidesmosomes in epithelia and costameres in striated muscle, anchorage to the nucleus or tight bundling of IFs opposes these dynamic processes.

The most thoroughly examined transport mode is the motor protein-driven transport of IFs and, more importantly, of IF assembly intermediates (Helfand et al. 2003a). Thus, IF particles known to be the precursors to fully assembled IFs have been identified as cargoes of myosins, dyneins, and kinesins. These motors are capable of transporting IF particles along actin filaments and microtubules in different directions over long distances to specific cellular subdomains. The attachment of these motor proteins to network-integrated IFs can provoke more-complex reactions. For example, they can contribute to overall network translocation within a cell (Fig. 2; and see Online Movie 1 at http://cshperspectives.cshlp.org) and might be responsible for the reported local filament undulations within the network (Ho et al. 1998; Yoon et al. 1998). An attractive hypothesis is that the activity of opposing motors contributes to intrinsic network tension and, hence, the mechanical resilience of the highly stretchable IFs. It should be kept in mind, however, that IFs are nonpolar and therefore cannot serve as tracks for unidirectional transport.

A much less investigated transport mechanism is the stable association of IFs to subunits of other cytoskeletal filaments, which undergo polymerization or depolymerization. This kind of transport could be mediated through cytoskeletal cross-linkers such as plectin, which connects IFs to actin filaments and microtubules (Sonnenberg and Liem 2007; Wiche and Winter 2011). Furthermore, the microtubule-binding protein adenomatous polyposis coli (APC) has been shown to link microtubules and vimentin in protruding extensions of migrating astrocytes, whereas kinesin and dynein motor proteins are of minor importance in this context (Sakamoto et al. 2013).

A third type of transport is diffusion. In practical terms, however, this process is only relevant for the soluble pool consisting of small oligomeric assembly stages. Comparatively little information is currently available on this topic. Besides early biochemical analyses (Soellner et al. 1985; Bachant and Klymkowsky 1996), fluorescence recovery after photobleaching (FRAP) and photoactivation experi- 

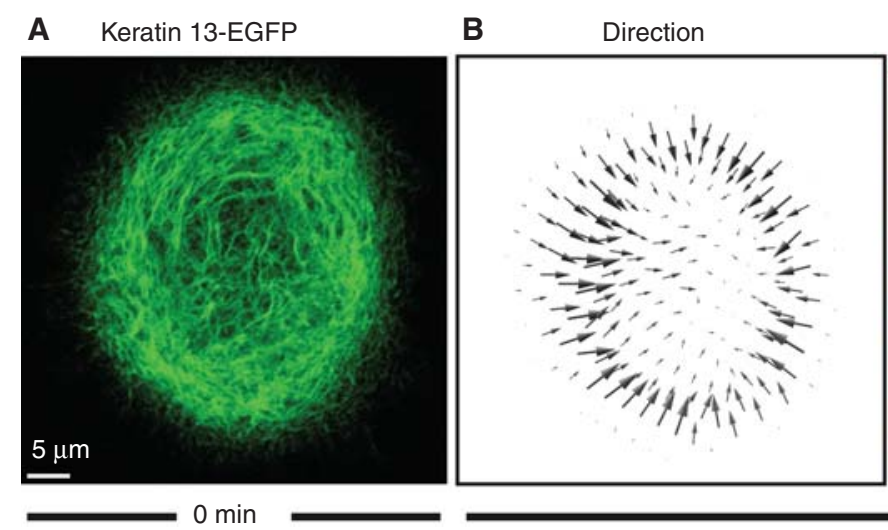

C

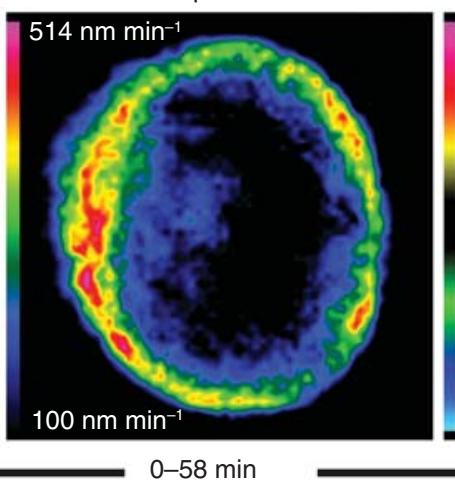

D Sources/sinks

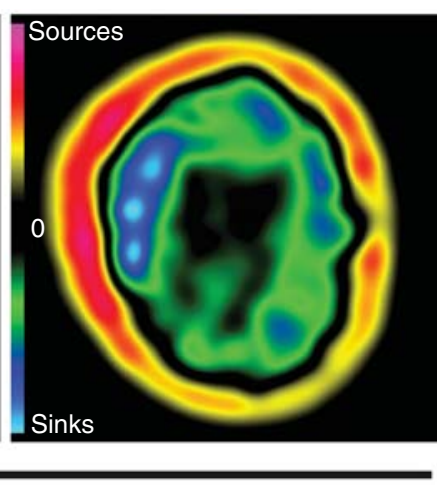

Figure 2. Imaging and measuring the coordinated keratin network motility in a cultured epithelial cell. The confocal laser scanning recording in $A$ shows the distribution of fluorescence-tagged keratins (keratin 13 tagged to enhanced green fluorescent protein [EGFP]) in a living cultured human A431 cell (derived from a squamous cell carcinoma) $1 \mathrm{~h}$ after addition of $2 \mathrm{ng} / \mathrm{mL}$ epidermal growth factor (EGF). Images were recorded at 30-sec intervals for $57.5 \mathrm{~min}$ (see Online Movie 1 at http://cshperspectives.cshlp.org). A deformable registration algorithm was used to determine the direction and speed of keratin motility during this interval (depicted as a vector diagram in $B$ and as a speed heat map in $C$; for details, see Moch et al. 2013). These data were then used to map keratin turnover $(D)$, revealing regions of net assembly ("sources," red) and net disassembly ("sinks," blue). The color-coded heat map in $D$ shows that assembly occurs predominantly in the cell periphery and disassembly predominantly in the central cytoplasm.

ments, both in vitro and in vivo, have provided some information on the properties of this rapidly diffusing pool (Yoon et al. 1998; Yoon et al. 2001; Windoffer et al. 2004; Kaminsky et al. 2009; Kölsch et al. 2010; Leube et al. 2011; Robert et al. 2015). The partial fluorescence recovery of bleached IFs and IF bundles, the assembly of filamentous material from nonbleached, nonfilamentous material, and the incorporation of bleached material into nonbleached cell regions, as well as the incorporation of nonfilamentous photoactivated material into filament bundles, are all indirect experimental evidence for the pancytoplasmic production and availability of diffusible IF proteins. In addition, bleaching of filament-free regions has provided a rough estimate for the diffusion constant of this soluble pool. More precise measurements, however, using, for example, fluorescence correlation spectroscopy (FCS) (Robert et al. 2015) are clearly needed to further characterize the subcellular and cell type-specific distribution patterns and determine the size of the diffusible assembly units.

A major distinguishing feature of IFs is their high degree of elasticity. Single filaments can be stretched up to 3.6-fold (Kreplak et al.2005), and loss of IFs has been shown to affect the elastic behavior of cultured cells (Ramms et al. 2013; Seltmann et al. 2013; Mendez et al. 2014). The anchorage of IFs to cellular organelles and distinct plasma membrane sites and the activity of motor proteins might therefore strain IFs, which are expected to retract and recoil on release. This is actually observed when microtubules, actin filaments, and cell-cell adhesions are disrupted (Goldman 1971; Woll et al. 2005; Waschke and Spindler 2014).

\section{IF MOTILITY IS DETERMINED BY ACTIN FILAMENTS AND MICROTUBULES}

Analyses of active IF particle transport has uncovered two fundamentally different signatures (Helfand et al. 2003a; Woll et al. 2005). One is characterized by a comparatively fast velocity of several microns per minute. Movement is discontinuous in a stop-and-go fashion and can be reversed. The other one is much slower and in the range of up to several hundred nanometers per minute. It is continuous and unidirectional (Fig. 2). Disruption of microtubules has been shown to abrogate the rapid, discontinuous, and bidirectional mode, whereas disruption of actin filaments prevents the slower, continuous, and unidirectional mode (Ho et al. 1998; Francis et al. 2005; Woll et al. 2005; Kölsch et al. 2009). Microtubule-dependent transport is predominant in neurofilament-expressing neurons and vimentin-positive mesenchymal cells, whereas actin-dependent motility appears to be most important for keratin particle transport in cultured cells. However, keratin particles are able to use microtubules as alternatives in addition to actin filaments as transport tracks (Fig. 3). It is not known to what degree availability and differences in affinity determine the observed differences and local choices.

\section{IFS ARE CARGOES OF MOTOR PROTEINS}

A large number of studies have provided evidence for direct interactions of IFs and IF assembly intermediates with microtubule- and actin-based motor proteins. Association of the plus end-directed microtubule-dependent motor 

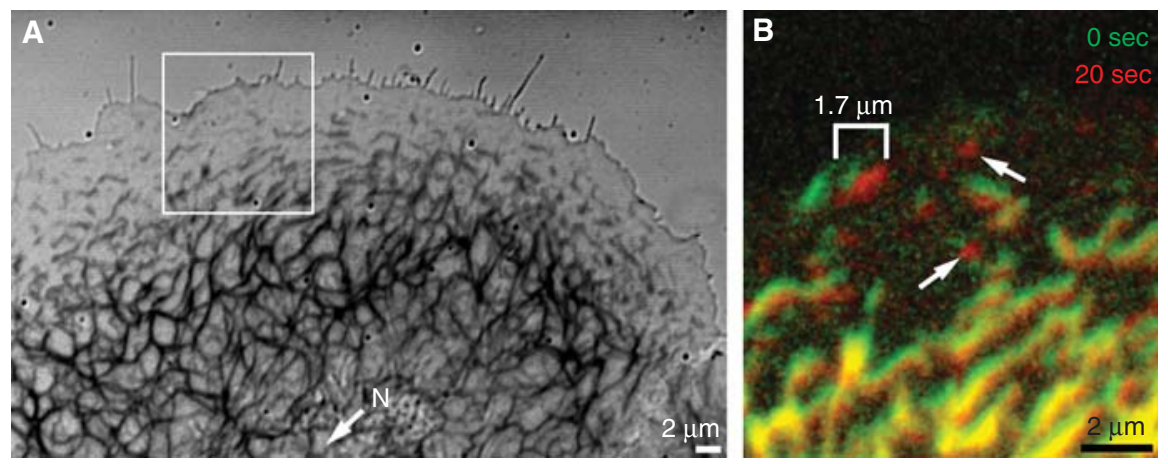

\begin{abstract}
Figure 3. Fast and slow transport of intermediate filaments (IFs). The photomicrographs depict part of a living vulva carcinoma-derived human A431 cell producing fluorescent keratin filaments. (A) Overlay of the recorded phase contrast and corresponding fluorescence images. Note the dense network in the cell center around the nucleus $(\mathrm{N})$, which tapers off toward the cell periphery, where only keratin particles are detectable. $(B)$ The fluorescence recorded in the boxed area in $A$ at two successive time points is shown as an overlay of the fluorescence at 0 sec in green and $20 \mathrm{sec}$ afterward in red. Note that most filaments and particles shifted only slightly toward the cell center (at bottom) as a consequence of slow, actin-dependent transport. A single particle, however, moved $1.7 \mu \mathrm{m}$ to the right because of rapid, microtubule-dependent transport (bracket). Arrows delineate two particles that nucleated de novo from the soluble keratin pool just before the time points shown here. A longer recording of the boxed area is presented in Online Movie 2 (see at http://cshperspectives.cshlp.org).
\end{abstract}

protein kinesin with vimentin, neurofilaments, and peripherin IF proteins has been proposed on the basis of immunofluorescence colocalization, coprecipitation, and kinesin-inhibition experiments (Gyoeva and Gelfand 1991; Prahlad et al. 1998; Yabe et al. 1999; Prahlad et al. 2000; Helfand et al. 2003b). Furthermore, it was shown that the tail region of the kinesin heavy chain and the kinesin light chain are needed for IF interactions and these interactions are initiated by detyrosination of tubulin (Liao and Gundersen 1998; Kreitzer et al. 1999). Postnatal depletion of the conventional kinesin heavy chain KIF5A results in neurofilament accumulation in the neuronal cell bodies (Xia et al. 2003).

Evidence has also been presented for interaction of the minus end-directed microtubule-dependent motor protein dynein with vimentin, neurofilaments, and peripherin (Shah et al. 2000; Helfand et al. 2002; Helfand et al. 2003b). It was shown that the neurofilament medium (NF-M) subunit binds directly to the dynein intermediate chain (Wagner et al. 2004). Dynein and kinesin can either bind exclusively to their respective cargoes or compete in a "tugof-war" for the same cargoes. The latter could be responsible for the intrinsic tension of the IF network, which is known to retract rapidly in a perinuclear cap on microtubule disruption (Goldman 1971).

An additional function has been proposed for microtubule-dependent motors in IF network biogenesis (Chang et al. 2006). It has been observed that translationally inactive peripherin messenger RNA (mRNA)-containing particles move along microtubules. Cessation of movement coincided with initiation of translation. This process, which is referred to as dynamic cotranslation, would allow cotranslational IF assembly for local network reorganization.

A lot less is known about the association of IFs with actin-dependent motor proteins. Nevertheless, the interaction between neurofilaments and myosin Va has been investigated in some detail (Rao et al. 2002, 2011) and reveals that it is mediated primarily through binding of the myosin head to the neurofilament light (NF-L) rod and is important for both neurofilament and myosin expression and distribution. Moreover, an important function of a keratin-myosin interaction has been recently assigned to the dissolution of mutant keratin aggregates (Kwan et al. 2015).

\section{THE DYNAMICS OF IFs ARE SUBJECT TO REGULATION}

Regulation of IF motility is determined by (1) structural linkers, (2) signaling pathways, and (3) posttranslational modification of IF polypeptides.

\subsection{Structural Linkers}

Linker-mediated attachment of IFs to dynamic structures results in passive transport, whereas attachment to static structures results in reduced network motility. Motor proteins are the prototype example of "piggyback" transporters. But other molecular components might also be relevant. For example, linkage of IFs to either actin filaments or microtubules is known to be mediated by the 
ubiquitous plakin-domain-containing cytolinker plectin (Sonnenberg and Liem 2007; Wiche and Winter 2011). In this way, IF motility could be coupled to actin retrograde flow and microtubule "treadmilling." Stabilization of IFs occurs through anchorage to hemidesmosomal and desmosomal adhesion sites and the nucleus. These interactions are also facilitated by plakin-domain proteins including, in addition to plectin, desmosomal desmoplakin (Sonnenberg and Liem 2007). Another determinant of IF motility is cross-linking between the filaments themselves. Intrinsic factors such as cysteine cross-linking and associated proteins such as filaggrins contribute to this process (Listwan and Rothnagel 2004; Feng and Coulombe 2015). Thus, dense IF bundles in suprabasal keratinocytes and the tight axonal IF bundles of neurons are presumably very static cellular components.

\subsection{Signaling Pathways}

A direct correlation between increased IF motility and signaling has been described for epidermal growth factor (EGF)-induced keratin network dynamics (Moch et al. 2013). A downstream component might be the Src protein-tyrosine kinase, which is induced upon wounding and could help to increase the plasticity of the IF cytoskeleton (Rotty and Coulombe 2012). Other pathways that probably affect IF motility are mediated by stress-induced mitogen-activated protein kinase (MAPK) (Woll et al. 2007) and small GTPases (Robert et al. 2014).

\subsection{Posttranslational Modifications}

Posttranslational modification of IF polypeptides has been the subject of intense research. Interestingly, activation of signaling pathways accompanies altered IF modification. In epithelial cells, for example, growth factor-induced EGF receptor activation and stress-induced MAPK signaling promote keratin phosphorylation, which coincides with altered network dynamics and modification (Woll et al. 2007; Moch et al. 2013). In neuronal cells, phosphorylation has been shown to affect transport efficiency. Phosphorylation of the neurofilament heavy (NF$\mathrm{H})$ chain and NF-M chain alters neurofilament association with kinesin and dynein (Yabe et al. 2000; Jung et al. 2005; Motil et al. 2006).

Decreased NF-H association with the anterograde motor kinesin coincides with the appearance of a carboxy-terminal phosphoepitope (Yabe et al. 1999) and correlates with increased NF-H association with the retrograde motor dynein (Motil et al. 2006). Furthermore, phosphoepitopes appear progressively as neurofilaments are transported from the cell body to the periphery (Nixon et al. 1994). Mice expressing NF-L with a phosphomimetic serine-to-aspartate mutation display accumulations of phosphorylated neurofilaments within cell bodies (Gibb et al. 1998).

Finally, sumoylation is another IF modification that is linked to network dynamics. Interference with sumoylation results in altered network exchange rates and organization in cultured human cells and in the epidermis of live Caenorhabditis elegans nematodes (Kaminsky et al. 2009; Snider et al. 2011).

\section{INTRACELLULAR IF MOTILITY IS AN ESSENTIAL FEATURE OF THE KERATIN TURNOVER CYCLE IN EPITHELIAL CELLS}

It has been shown for epithelial cells that IF network turnover continues in the absence of protein biosynthesis (Kölsch et al. 2010). This turnover occurs in cycles of multiple assembly-disassembly steps (Kölsch et al. 2010; Leube et al. 2011; Windoffer et al. 2011). Polymerization of particles from the soluble pool takes place primarily in the cell periphery, generating growing filaments that are integrated into the network. Depolymerization of mature keratin filaments, in contrast, occurs primarily in the central cytoplasm, giving rise to soluble and rapidly diffusible subunits that can be used for another cycle of assembly and disassembly. Assembly is a complex process with different intermediates: Nucleation of spheroidal particles takes place preferentially in the vicinity of focal adhesions. These particles subsequently elongate into filamentous structures, which can fuse to each other or integrate into the peripheral keratin network. Filaments within the network form increasingly thicker bundles. These different assembly and maturation processes are coupled to net movement toward the nucleus. The inward-directed motility is linked to the presence of actin filaments and microtubules.

Figure 2 presents an example of a single epithelial cell producing fluorescent protein-tagged keratin polypeptides. Online Movie 1 (see http://cshperspectives.cshlp .org) highlights the high degree of network dynamics due to the ongoing keratin turnover cycle. Image-analysis routines were applied to the images to deduce information on the direction and speed of keratin motility (Moch et al. 2013). The results were depicted as a vector diagram (Fig. 2B) and as a heatmap with subcellular resolution (Fig. 2C). The information contained in the images was further used to calculate the rates of bulk transport. These served as a basis for the heatmap (Fig. 2D) delineating sources of fluorescence, corresponding to regions of keratin assembly, and sinks of fluorescence, corresponding to regions of keratin disassembly. 


\section{NEURONAL IF MOTILITY DETERMINES AXONAL DIAMETER AND SLOW AXONAL TRANSPORT}

It is well accepted that the amount of neurofilaments and the ratio of their three integral polypeptide componentsNF-L, NF-M, and NF-H- determine axonal diameter and, hence, conduction velocity within these specialized cell processes (Dale and Garcia 2012). How an even axonal diameter is maintained over distances of up to $1 \mathrm{~m}$ in single cells, however, is not known. It is a task that requires precise and cell-specific instructions and regulatory mechanisms. Although neurofilaments are known to be extremely longlived structures, recent observations have shown that they are subject to continuous turnover all along their axonal processes (Fig. 4) (Roy et al. 2000; Wang et al. 2000; Brown et al. 2005). Small particles are added and released from the bundled filaments. As outlined above, these particles are transported anterogradely and retrogradely with the help of kinesin and dynein motors, respectively. The transport of neurofilament particles is characterized by a stop-and-go mechanism, whereby short phases of rapid transport are followed by comparatively long phases of no transport either in an "on-track" or an "off-track" state (Brown et al. 2005). The latter is caused by hopping off the microtubule track. Loss of motor protein binding facilitates alternative binding of a given IF particle to another type of motor protein in the next transport cycle, resulting in transport in the opposite direction. A slight bias of anterograde transport results in the long-known slow axonal transport toward the periphery.

\section{IF MOTILITY IS LINKED TO CELL MIGRATION}

Mesenchyme-derived vimentin IF-expressing leukocytes and fibroblasts are specialized for migration. It is therefore no surprise that key observations in vimentin-free fibroblasts concern deficiencies in migration. Recently, vimentin has been shown to be directly involved in outgrowth of the lens epithelium in a wound-healing model (Menko et al.

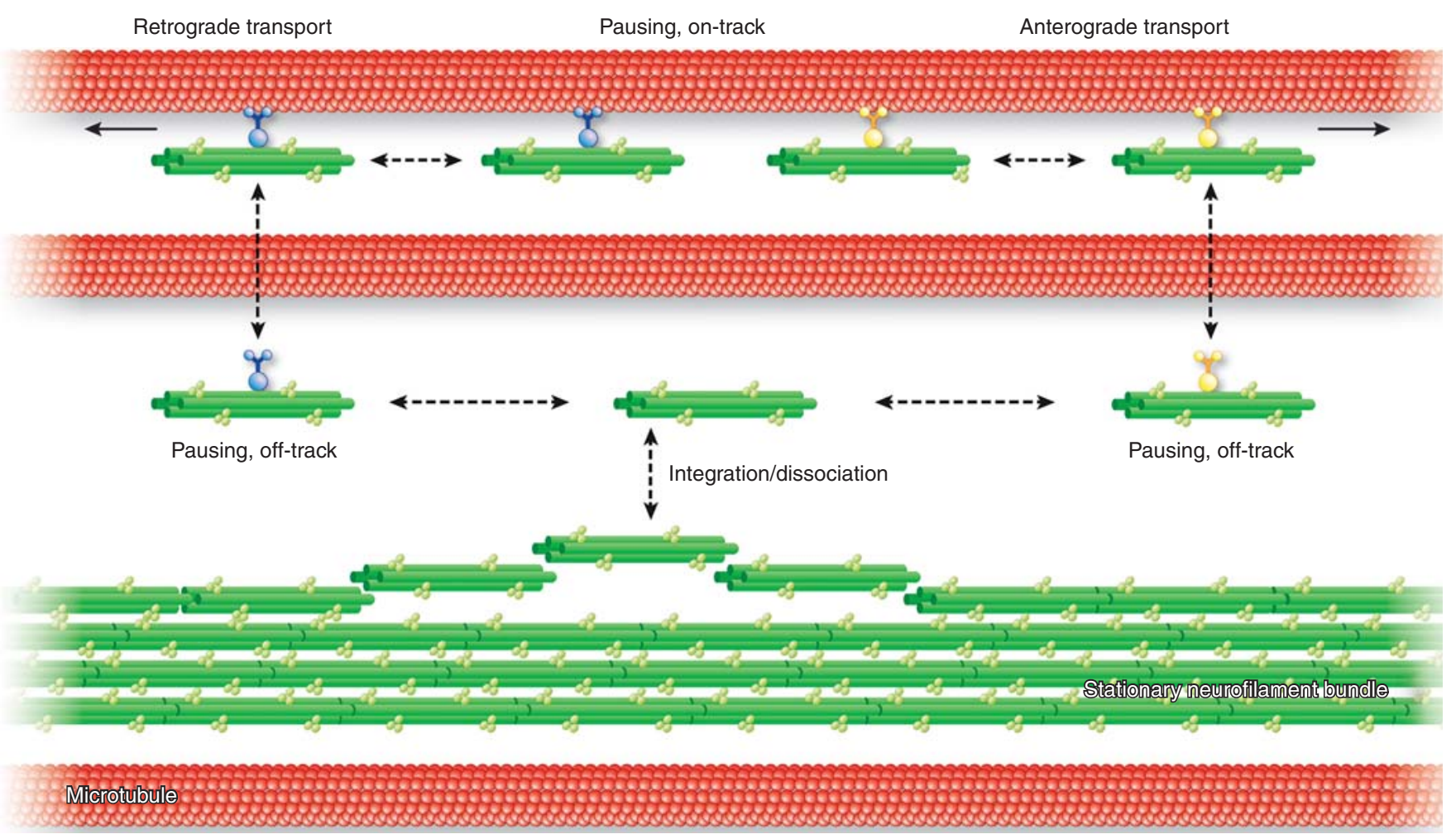

Figure 4. Scheme of neuronal intermediate filament (IF) network motility. The diagram depicts neurofilamentcontaining IFs (green) and microtubules (red) in a segment of a neuronal axon. Neurofilaments are illustrated as tight bundles that are interspersed between single microtubules. Small filamentous neurofilament particles of up to $100 \mu \mathrm{m}$ are continuously released and reincorporated into the bundled IFs. These short IF-like particles can associate with either minus end-directed dynein or plus end-directed kinesin motors to be transported along microtubules in opposite directions. Both types of transport are discontinuous, with long pauses either in an ontrack or off-track fashion. Taken together, an overall slow transport is attained, with a net movement toward the microtubule plus end. 
R.E. Leube et al.

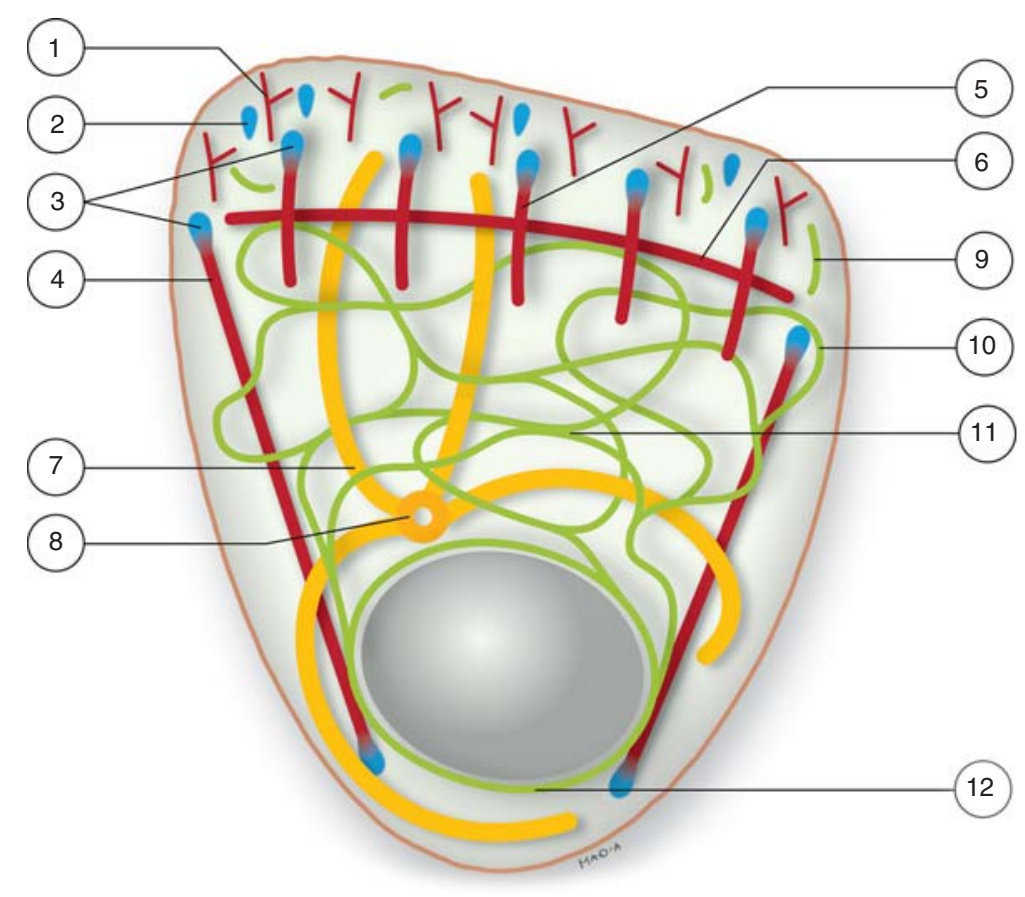

Figure 5. Schematic of the polarized cytoskeletal network in a migrating epithelial cell. Cell migration requires cellular polarization, resulting in a leading edge (top) and trailing edge (bottom). It requires the concerted action of all major cytoskeletal filament systems and is closely linked to extracellular matrix adhesion sites. At the leading edge, branched actin filaments (1) are involved in the protrusion of the lamellum, where nascent focal complexes (2) mature into focal adhesions (3). The latter are linked to actin- and myosin-containing ventral stress fibers (4), which traverse the cell body toward the rear, and dorsal stress fibers (5) that are connected by transverse arcs (6). Microtubules (7), which originate from the microtubule-organizing center (8), extend with their plus ends into the lamellum. The epithelial keratin intermediate filaments (IFs) nucleate preferentially in the vicinity of focal adhesions, where elongating keratin particles appear (9) that are transported toward the cell interior and integrate into the peripheral network (10), resulting in network extension toward the leading edge. The keratin network presents bundled filaments in the central cytoplasm (11) and surrounds the nucleus as a cage-like structure (12).

2014). Mechanistically, it is not clear how this is accomplished. But vimentin network retraction is linked to lamellipodia formation in murine fibroblasts. The retraction of vimentin filaments can be induced in serum-starved cells by addition of serum and by local activation of small GTPases, coincident with phosphorylation of vimentin (Helfand et al. 2011). Regulation of GTPase activity has also been shown to affect microtubule-dependent transport of vimentin assembly intermediates (Robert et al. 2014). The above-mentioned binding of APC to vimentin in migrating cells, which presumably promotes vimentin polymerization (Sakamoto et al. 2013), is another factor in this scenario. Whether microtubules push the vimentin network forward, or vice versa, needs to be examined. In addition, cross talk between the vimentin filament system and focal adhesions further contributes to cell migration (Gregor et al. 2014). Transendothelial migration of vimentin-positive cells, which can occur either between endothelial cells or directly through the endothelial cytoplasm, requires additional directional cues to guide and relocate the vimentin network (Nieminen et al. 2006).

EGF is known to induce increased motility in epithelial cells and to alter the architecture of cytoskeletal networks (Fig. 5). It has recently been shown that EGF increases the inward-directed motility of the keratin network and results in increased keratin network turnover (Moch et al. 2013). This is also coupled to increased phosphorylation of keratins. How these different phenomena are connected to cell migration remains to be established.

\section{STRESS INDUCES ALTERATIONS IN IF MOTILITY}

The IF network acts as a major stress protector against various types of insult. In epithelial cells, stress-induced p38 MAPK activation has been shown to affect the dynamics of keratin networks. Inhibition of p38 MAPK prevents keratin nucleation and disassembly, thereby leading to increased network stabilization (Woll et al. 2007). In contrast, 
increased p38 MAPK activity results in the formation of motile keratin aggregates. These aggregates and similar aggregates, which are generated in certain stress situations during mitosis and upon expression of mutant keratins, contain activated p38 MAPK (Woll et al. 2007).

The complex interaction between IF motility, signaling pathways, and cell stress is highlighted during nerve injury (Perlson et al. 2005). It has been reported that an axonal lesion induces local synthesis of soluble vimentin, which is used to transport activated phosphorylated extracellular signal-regulated kinases (pERKs) retrogradely to the cell body by direct interaction with the dynein complex. The reduced $\mathrm{Ca}^{2+}$ concentration in the cell body then leads to dissociation of pERKs from vimentin to target downstream effectors in the cell body and nucleus.

Comparatively little is known about IF network dynamics and microbial infections (Geisler and Leube 2016). A fascinating situation, however, is encountered during infection with enteropathogenic Escherichia coli. The extracellular bacteria induce the formation of actinrich pedestals in the cytoplasm of the intestinal cells underneath the bacteria. It has been shown that keratins are recruited by a translocated bacterial adaptor protein to facilitate actin reorganization in newly forming pedestals (Batchelor et al. 2004). Papilloma virus infection of epithelial cells provides another example of infection-induced altered IF network dynamics. In this case, HPV16 E1^E4 protein has been reported to induce keratin network reorganization accompanied by keratin hyperphosphorylation and drastic reduction of keratin motility (McIntosh et al. 2010).

\section{DISTURBANCES OF INTRACELLULAR IF MOTILITY ARE LINKED TO DISEASE}

A consequence of perturbed IF motility is dysfunctional network formation and local accumulation of mistargeted proteins. Thus, IF-containing cytoplasmic aggregates have been observed in many diseases, including liver cirrhosis, neurodegeneration, giant axonal neuropathy, glial Alexander disease, and myopathies (Goebel 2003; Liem and Messing 2009; Strnad et al. 2013). In agreement with this concept, mice overexpressing the p50/dynamitin subunit of dynactin, which interferes with dynein function, develop motor neuron disease, which is characterized by axonal neurofilament accumulations (LaMonte et al. 2002).

\section{CONCLUSION}

IF motility is integral to homeostatic cell function and is key to cellular plasticity. Cell type- and context-dependent fine-tuning of IF motility is reflected by multimodality, complex interactions with structural cell components, and regulation by multiple signaling pathways. The current challenge is to correlate these different processes with defined molecular events.

\section{ACKNOWLEDGMENTS}

We thank Adam Breitscheidel for expert help with Figures 1,4 , and 5. Our work was supported by the German Research Council (LE 566/14; LE 566/18; LE 566/20; LE 566/22; WI 1731/6; WI 1731/8), a European Respiratory Society (ERS) grant by RWTH Aachen University, a Zentrum für Interdisciplinäre Klinische Forschung (IZKF) grant by the Uniklinik RWTH Aachen University (T11-1), and the European Union (EU) H2020-MSCA-ITN InCeM (642866).

\section{REFERENCES}

* Reference is also in this subject collection.

Bachant JB, Klymkowsky MW. 1996. A nontetrameric species is the major soluble form of keratin in Xenopus oocytes and rabbit reticulocyte lysates. J Cell Biol 132: 153-165.

Batchelor M, Guignot J, Patel A, Cummings N, Cleary J, Knutton S, Holden DW, Connerton I, Frankel G. 2004. Involvement of the intermediate filament protein cytokeratin-18 in actin pedestal formation during EPEC infection. EMBO Rep 5: 104-110.

Brown A, Wang L, Jung P. 2005. Stochastic simulation of neurofilament transport in axons: The "stop-and-go" hypothesis. Mol Biol Cell 16: 4243-4255.

Carberry K, Wiesenfahrt T, Geisler F, Stöcker S, Gerhardus H, Überbach D, Davis W, Jorgensen E, Leube RE, Bossinger O. 2012. The novel intestinal filament organizer IFO-1 contributes to epithelial integrity in concert with ERM-1 and DLG-1. Development 139: 1851-1862.

Chang L, Shav-Tal Y, Trcek T, Singer RH, Goldman RD. 2006. Assembling an intermediate filament network by dynamic cotranslation. J Cell Biol 172: $747-758$.

Dale JM, Garcia ML. 2012. Neurofilament phosphorylation during development and disease: Which came first, the phosphorylation or the accumulation? J Amino Acids 2012: 382107.

Feng X, Coulombe PA. 2015. A role for disulfide bonding in keratin intermediate filament organization and dynamics in skin keratinocytes. J Cell Biol 209: 59-72.

Francis F, Roy S, Brady ST, Black MM. 2005. Transport of neurofilaments in growing axons requires microtubules but not actin filaments. $J$ Neurosci Res 79: 442-450.

Geisler F, Leube RE. 2016. Epithelial intermediate filaments: Guardians against microbial infection? Cells 5: 29.

Gibb BJ, Brion JP, Brownlees J, Anderton BH, Miller CC. 1998. Neuropathological abnormalities in transgenic mice harbouring a phosphorylation mutant neurofilament transgene. J Neurochem 70: 492-500.

Goebel HH. 2003. Congenital myopathies at their molecular dawning. Muscle Nerve 27: 527-548.

Goldman RD. 1971. The role of three cytoplasmic fibers in BHK-21 cell motility. I. Microtubules and the effects of colchicine. J Cell Biol 51: $752-762$.

Gregor M, Osmanagic-Myers S, Burgstaller G, Wolfram M, Fischer I, Walko G, Resch GP, Jorgl A, Herrmann H, Wiche G. 2014. Mechanosensing through focal adhesion-anchored intermediate filaments. FASEB J 28: 715-729. 
R.E. Leube et al.

Gyoeva FK, Gelfand VI. 1991. Coalignment of vimentin intermediate filaments with microtubules depends on kinesin. Nature 353: 445-448.

Helfand BT, Mikami A, Vallee RB, Goldman RD. 2002. A requirement for cytoplasmic dynein and dynactin in intermediate filament network assembly and organization. J Cell Biol 157: 795-806.

Helfand BT, Chang L, Goldman RD. 2003a. The dynamic and motile properties of intermediate filaments. Annu Rev Cell Dev Biol 19: 445-467.

Helfand BT, Loomis P, Yoon M, Goldman RD. 2003b. Rapid transport of neural intermediate filament protein. J Cell Sci 116: 2345-2359.

Helfand BT, Mendez MG, Murthy SN, Shumaker DK, Grin B, Mahammad S, Aebi U, Wedig T, Wu YI, Hahn KM, et al. 2011. Vimentin organization modulates the formation of lamellipodia. Mol Biol Cell 22: $1274-1289$.

* Herrmann H, Aebi U. 2016. Intermediate filaments: Structure and assembly. Cold Spring Harb Perspect Biol doi: 101101/cshperspect .a018242.

Ho CL, Martys JL, Mikhailov A, Gundersen GG, Liem RK. 1998. Novel features of intermediate filament dynamics revealed by green fluorescent protein chimeras. J Cell Sci 111: 1767-1778.

Iwatsuki H, Suda M. 2010. Seven kinds of intermediate filament networks in the cytoplasm of polarized cells: Structure and function. Acta Histochem Cytochem 43: 19-31.

Jung C, Lee S, Ortiz D, Zhu Q, Julien JP, Shea TB. 2005. The high and middle molecular weight neurofilament subunits regulate the association of neurofilaments with kinesin: Inhibition by phosphorylation of the high molecular weight subunit. Brain Res Mol Brain Res 141: $151-155$

Kaminsky R, Denison C, Bening-Abu-Shach U, Chisholm AD, Gygi SP, Broday L. 2009. SUMO regulates the assembly and function of a cytoplasmic intermediate filament protein in C. elegans. Dev Cell 17: $724-735$.

Kölsch A, Windoffer R, Leube RE. 2009. Actin-dependent dynamics of keratin filament precursors. Cell Motil Cytoskeleton 66: 976-985.

Kölsch A, Windoffer R, Wurflinger T, Aach T, Leube RE. 2010. The keratinfilament cycle of assembly and disassembly. J Cell Sci 123: 2266-2272.

Kreitzer G, Liao G, Gundersen GG. 1999. Detyrosination of tubulin regulates the interaction of intermediate filaments with microtubules in vivo via a kinesin-dependent mechanism. Mol Biol Cell 10: 11051118.

Kreplak L, Bar H, Leterrier JF, Herrmann H, Aebi U. 2005. Exploring the mechanical behavior of single intermediate filaments. J Mol Biol 354: 569-577.

Kwan R, Chen L, Looi K, Tao GZ, Weerasinghe SV, Snider NT, Conti MA, Adelstein RS, Xie Q, Omary MB. 2015. PKC412 normalizes mutation-related keratin filament disruption and hepatic injury in mice by promoting keratin-myosin binding, Hepatology 62: 18581869.

LaMonte BH, Wallace KE, Holloway BA, Shelly SS, Ascano J, Tokito M, Van Winkle T, Howland DS, Holzbaur EL. 2002. Disruption of dynein/dynactin inhibits axonal transport in motor neurons causing late-onset progressive degeneration. Neuron 34: 715-727.

Leube RE, Moch M, Kölsch A, Windoffer R. 2011. "Panta rhei”: Perpetual cycling of the keratin cytoskeleton. Bioarchitecture 1: 39-44.

Liao G, Gundersen GG. 1998. Kinesin is a candidate for cross-bridging microtubules and intermediate filaments. Selective binding of kinesin to detyrosinated tubulin and vimentin. J Biol Chem 273: 97979803.

Liem RK, Messing A. 2009. Dysfunctions of neuronal and glial intermediate filaments in disease. J Clin Invest 119: 1814-1824.

Listwan P, Rothnagel JA. 2004. Keratin bundling proteins. Methods Cell Biol 78: 817-827.

McIntosh PB, Laskey P, Sullivan K, Davy C, Wang Q, Jackson DJ, Griffin HM, Doorbar J. 2010. E1^E4-mediated keratin phosphorylation and ubiquitylation: A mechanism for keratin depletion in HPV16-infected epithelium. J Cell Sci 123: 2810-2822.
Mendez MG, Restle D, Janmey PA. 2014. Vimentin enhances cell elastic behavior and protects against compressive stress. Biophys J 107: 314323.

Menko AS, Bleaken BM, Libowitz AA, Zhang L, Stepp MA, Walker JL. 2014. A central role for vimentin in regulating repair function during healing of the lens epithelium. Mol Biol Cell 25: 776-790.

Moch M, Herberich G, Aach T, Leube RE, Windoffer R. 2013. Measuring the regulation of keratin filament network dynamics. Proc Natl Acad Sci 110: $10664-10669$.

Motil J, Chan WK, Dubey M, Chaudhury P, Pimenta A, Chylinski TM, Ortiz DT, Shea TB. 2006. Dynein mediates retrograde neurofilament transport within axons and anterograde delivery of NFs from perikarya into axons: Regulation by multiple phosphorylation events. Cell Motil Cytoskeleton 63: 266-286.

Nieminen M, Henttinen T, Merinen M, Marttila-Ichihara F, Eriksson JE, Jalkanen S. 2006. Vimentin function in lymphocyte adhesion and transcellular migration. Nat Cell Biol 8: 156-162.

Nixon RA, Paskevich PA, Sihag RK, Thayer CY. 1994. Phosphorylation on carboxyl terminus domains of neurofilament proteins in retinal ganglion cell neurons in vivo: Influences on regional neurofilament accumulation, interneurofilament spacing, and axon caliber. J Cell Biol 126: $1031-1046$.

Perlson E, Hanz S, Ben-Yaakov K, Segal-Ruder Y, Seger R, Fainzilber M. 2005. Vimentin-dependent spatial translocation of an activated MAP kinase in injured nerve. Neuron 45: 715-726.

Prahlad V, Yoon M, Moir RD, Vale RD, Goldman RD. 1998. Rapid movements of vimentin on microtubule tracks: Kinesindependent assembly of intermediate filament networks. J Cell Biol 143: $159-170$.

Prahlad V, Helfand BT, Langford GM, Vale RD, Goldman RD. 2000. Fast transport of neurofilament protein along microtubules in squid axoplasm. J Cell Sci 113: 3939-3946.

Ramms L, Fabris G, Windoffer R, Schwarz N, Springer R, Zhou C, Lazar J, Stiefel S, Hersch N, Schnakenberg U, et al. 2013. Keratins as the main component for the mechanical integrity of keratinocytes. Proc Natl Acad Sci 110: 18513-18518.

Rao MV, Engle LJ, Mohan PS, Yuan A, Qiu D, Cataldo A, Hassinger L, Jacobsen S, Lee VM, Andreadis A, et al. 2002. Myosin Va binding to neurofilaments is essential for correct myosin Va distribution and transport and neurofilament density. J Cell Biol 159: 279-290.

Rao MV, Mohan PS, Kumar A, Yuan A, Montagna L, Campbell J, Veeranna, Espreafico EM, Julien JP, Nixon RA. 2011. The myosin Va head domain binds to the neurofilament- $\mathrm{L}$ rod and modulates endoplasmic reticulum (ER) content and distribution within axons. PLoS ONE 6: e17087.

Robert A, Herrmann H, Davidson MW, Gelfand VI. 2014. Microtubuledependent transport of vimentin filament precursors is regulated by actin and by the concerted action of Rho- and p21-activated kinases. FASEB J 28: 2879-2890.

Robert A, Rossow MJ, Hookway C, Adam SA, Gelfand VI. 2015. Vimentin filament precursors exchange subunits in an ATP-dependent manner. Proc Natl Acad Sci 112: 3505-3514.

Rotty JD, Coulombe PA. 2012. A wound-induced keratin inhibits Src activity during keratinocyte migration and tissue repair. J Cell Biol 197: $381-389$.

Roy S, Coffee P, Smith G, Liem RK, Brady ST, Black MM. 2000. Neurofilaments are transported rapidly but intermittently in axons: Implications for slow axonal transport. J Neurosci 20: 68496861.

Sakamoto Y, Boeda B, Etienne-Manneville S. 2013. APC binds intermediate filaments and is required for their reorganization during cell migration. J Cell Biol 200: 249-258.

Seltmann K, Fritsch AW, Kas JA, Magin TM. 2013. Keratins significantly contribute to cell stiffness and impact invasive behavior. Proc Natl Acad Sci 110: 18507-18512. 
Shah JV, Flanagan LA, Janmey PA, Leterrier JF. 2000. Bidirectional translocation of neurofilaments along microtubules mediated in part by dynein/dynactin. Mol Biol Cell 11: 3495-3508.

Snider NT, Weerasinghe SV, Iniguez-Lluhi JA, Herrmann H, Omary MB. 2011. Keratin hypersumoylation alters filament dynamics and is a marker for human liver disease and keratin mutation. J Biol Chem 286: $2273-2284$.

Soellner P, Quinlan RA, Franke WW. 1985. Identification of a distinct soluble subunit of an intermediate filament protein: Tetrameric vimentin from living cells. Proc Natl Acad Sci 82: 7929-7933.

Sonnenberg A, Liem RK. 2007. Plakins in development and disease. Exp Cell Res 313: 2189-2203.

Strnad P, Nuraldeen R, Guldiken N, Hartmann D, Mahajan V, Denk H, Haybaeck J. 2013. Broad spectrum of hepatocyte inclusions in humans, animals, and experimental models. Compr Physiol 3: 1393-1436.

Wagner OI, Ascano J, Tokito M, Leterrier JF, Janmey PA, Holzbaur EL. 2004. The interaction of neurofilaments with the microtubule motor cytoplasmic dynein. Mol Biol Cell 15: 5092-5100.

Wang L, Ho CL, Sun D, Liem RK, Brown A. 2000. Rapid movement of axonal neurofilaments interrupted by prolonged pauses. Nat Cell Biol 2: $137-141$.

Waschke J, Spindler V. 2014. Desmosomes and extradesmosomal adhesive signaling contacts in pemphigus. Med Res Rev 34: 1127-1145.

Wiche G, Winter L. 2011. Plectin isoforms as organizers of intermediate filament cytoarchitecture. Bioarchitecture 1: 14-20.

Windoffer R, Leube RE. 1999. Detection of cytokeratin dynamics by time-lapse fluorescence microscopy in living cells. J Cell Sci 112: $4521-4534$.
Windoffer R, Woll S, Strnad P, Leube RE. 2004. Identification of novel principles of keratin filament network turnover in living cells. Mol Biol Cell 15: 2436-2448.

Windoffer R, Beil M, Magin TM, Leube RE. 2011. Cytoskeleton in motion: The dynamics of keratin intermediate filaments in epithelia. J Cell Biol 194: 669-678.

Woll S, Windoffer R, Leube RE. 2005. Dissection of keratin dynamics: Different contributions of the actin and microtubule systems. Eur $J$ Cell Biol 84: 311-328.

Woll S, Windoffer R, Leube RE. 2007. p38 MAPK-dependent shaping of the keratin cytoskeleton in cultured cells. J Cell Biol 177: 795807.

Xia CH, Roberts EA, Her LS, Liu X, Williams DS, Cleveland DW, Goldstein LS. 2003. Abnormal neurofilament transport caused by targeted disruption of neuronal kinesin heavy chain KIF5A. J Cell Biol 161: 55-66.

Yabe JT, Pimenta A, Shea TB. 1999. Kinesin-mediated transport of neurofilament protein oligomers in growing axons. J Cell Sci 112: 37993814.

Yabe JT, Jung C, Chan WK, Shea TB. 2000. Phospho-dependent association of neurofilament proteins with kinesin in situ. Cell Motil Cytoskeleton 45: 249-262.

Yoon M, Moir RD, Prahlad V, Goldman RD. 1998. Motile properties of vimentin intermediate filament networks in living cells. J Cell Biol 143: 147-157.

Yoon KH, Yoon M, Moir RD, Khuon S, Flitney FW, Goldman RD. 2001. Insights into the dynamic properties of keratin intermediate filaments in living epithelial cells. J Cell Biol 153: 503-516. 


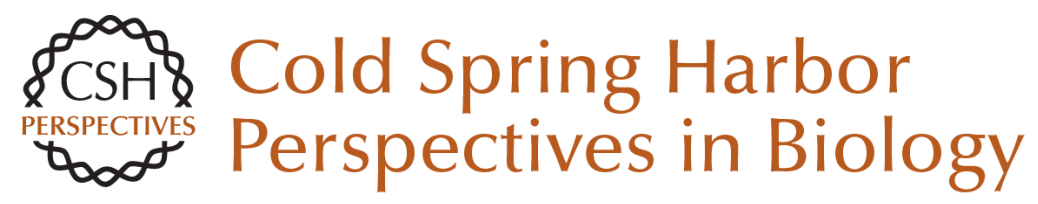

\section{Intracellular Motility of Intermediate Filaments}

Rudolf E. Leube, Marcin Moch and Reinhard Windoffer

Cold Spring Harb Perspect Biol 2017; doi: 10.1101/cshperspect.a021980

Subject Collection The Cytoskeleton

Microtubules and Microtubule-Associated

Proteins

Holly V. Goodson and Erin M. Jonasson

Motor Proteins

H. Lee Sweeney and Erika L.F. Holzbaur

Myosin-Driven Intracellular Transport Margaret A. Titus

The Actin Cytoskeleton and Actin-Based Motility Tatyana Svitkina

\section{Mechanical Properties of the Cytoskeleton and Cells \\ Adrian F. Pegoraro, Paul Janmey and David A.} Weitz

Intermediate Filaments and the Regulation of Cell Motility during Regeneration and Wound Healing Fang Cheng and John E. Eriksson

Intermediate Filaments and the Plasma Membrane Jonathan C.R. Jones, Chen Yuan Kam, Robert M. Harmon, et al.

Intracellular Motility of Intermediate Filaments Rudolf E. Leube, Marcin Moch and Reinhard Windoffer

\section{Overview of the Cytoskeleton from an}

Evolutionary Perspective

Thomas D. Pollard and Robert D. Goldman

Types I and II Keratin Intermediate Filaments Justin T. Jacob, Pierre A. Coulombe, Raymond Kwan, et al.

Muscle Contraction

H. Lee Sweeney and David W. Hammers

Type III Intermediate Filaments Desmin, Glial

Fibrillary Acidic Protein (GFAP), Vimentin, and

Peripherin

Elly M. Hol and Yassemi Capetanaki

Cytokinesis in Metazoa and Fungi Michael Glotzer

Ciliary Motility: Regulation of Axonemal Dynein Motors

Rasagnya Viswanadha, Winfield S. Sale and Mary

E. Porter

Actin-Based Adhesion Modules Mediate Cell Interactions with the Extracellular Matrix and Neighboring Cells

Alexia I. Bachir, Alan Rick Horwitz, W. James Nelson, et al.

Microtubule-Based Transport and the Distribution,

Tethering, and Organization of Organelles Kari Barlan and Vladimir I. Gelfand

For additional articles in this collection, see http://cshperspectives.cshlp.org/cgi/collection/

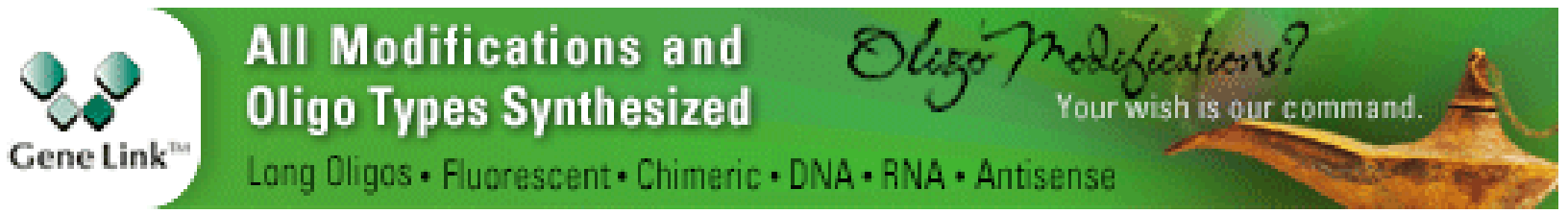

Copyright @ 2017 Cold Spring Harbor Laboratory Press; all rights reserved 
For additional articles in this collection, see http://cshperspectives.cshlp.org/cgi/collection/

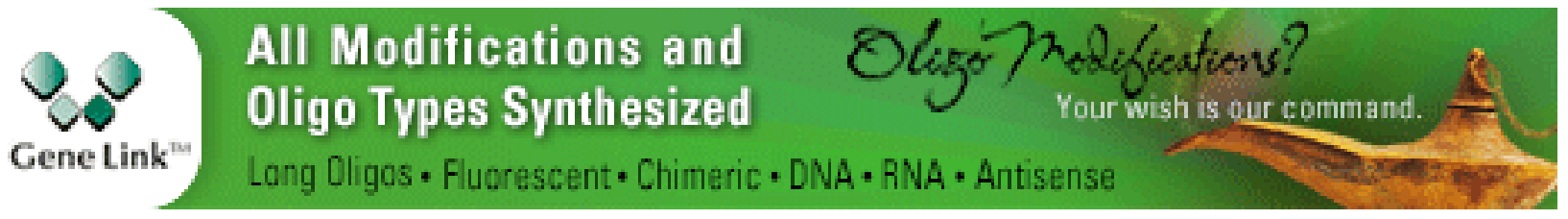

Copyright @ 2017 Cold Spring Harbor Laboratory Press; all rights reserved 